\title{
Oxidative stress impairs nuclear proteins binding to the insulin responsive element in the GLUT4 promoter
}

\author{
D.Pessler ${ }^{1}$, A. Rudich ${ }^{1,2}$, N. Bashan ${ }^{1,3}$ \\ ${ }^{1}$ Department of Clinical Biochemistry, Faculty of Health Science, Ben-Gurion University of the Negev, Beer-Sheva, Israel \\ ${ }^{2}$ The S. Daniel Abraham Center for Health and Nutrition, Faculty of Health Sciences, Ben-Gurion University of the Negev, Beer- \\ Sheva, Israel \\ ${ }^{3}$ The Leslie and Susan Gonda (Goldschmied) Laboratory for Multi-disciplinary Diabetes Research, Faculty of Health Science, \\ Ben-Gurion University of the Negev, Beer-Sheva, 84103, Israel
}

\begin{abstract}
Aims/hypothesis. Substantial evidence suggests an important role for the expression of GLUT4 in adipocytes, in the pathogenesis of insulin resistance and Type II (non-insulin-dependent) diabetes mellitus. We investigated whether oxidative stress decreases GLUT4 expression by impairing DNA binding of nuclear proteins to the insulin responsive element in the GLUT4 promoter.

Methods. 3T3-L1 adipocytes were exposed to micromolar $\mathrm{H}_{2} \mathrm{O}_{2}$ concentrations and GLUT4 expression and binding of nuclear proteins to defined DNA sequences were assessed.

Results. GLUT4 mRNA was decreased after at least $4 \mathrm{~h}$ exposure to $\mathrm{H}_{2} \mathrm{O}_{2}$, without a major change in the stability of GLUT4 transcripts. Nuclear protein extracts prepared from oxidized cells showed decreased binding to the insulin responsive element of the GLUT4 promoter but not to other DNA sequences.
\end{abstract}

The direct effect of oxidation on the binding to the insulin response element was shown by the observation that in vitro oxidation of nuclear extracts with $\mathrm{H}_{2} \mathrm{O}_{2}$, N-ethylmaleimide or diamide decreased proteinDNA complex formation. This, and decreased binding capacity observed in nuclear extracts from oxidized cells, were partly reversible by subsequent treatment with a reducing agent. Protein binding to a consensus DNA sequence for nuclear factor 1 transcription factors was decreased $16 \%$ by oxidation, whereas no change was observed in the protein content of several isoforms of these proteins.

Conclusion/interpretation. Oxidative stress causes decreased GLUT4 expression, associated with impaired binding of nuclear proteins to the insulin responsive element in the GLUT4 promoter. [Diabetologia (2001) 44: 2156-2164]

Keywords Nuclear factor 1 , insulin resistance, adipose tissue, hydrogen peroxide.
Accumulating experimental evidence suggests that the expression of the insulin responsive glucose trans-

Received: 13 June 2001 and in revised form: 20 August 2001

Corresponding author: N. Bashan, The Leslie and Susan Gonda (Goldschmied) Laboratory for Multi-disciplinary Diabetes Research, Faculty of Health Science, Ben-Gurion University of the Negev, Beer-Sheva, 84103, Israel, e-mail: nava@bgumail.bgu.ac.il

Abbreviations: C/EBP, CCAAT element binding protein; DTT, dithiothreitol; EMSA, electrophoretic mobility shift assay; GSH, glutathione; IRE, insulin responsive element; NEM, Nethylmaleimide; NF1, nuclear factor 1; $P P A R \gamma$, peroxisome proliferator activator receptor gamma; PPRE, PPAR response element; ISGT, insulin stimulated glucose transport porter GLUT4 could be central in determining peripheral insulin sensitivity and thus could be an important factor in the pathogenesis of Type II (non-insulin-dependent) diabetes mellitus [1, 2]. Various groups have shown that GLUT4 expression in adipose tissue is reduced in obese, non-diabetic subjects, and more so in Type II diabetic patients [3, 4]. Studies in animal models of diabetes have also measured GLUT4 mRNA content and its transcription rate in adipose tissue, mostly showing a role for transcriptional regulation of the GLUT4 gene [5-8]. Moreover, a causative role for decreased adipose tissue GLUT4 expression in the diabetic phenotype has been suggested. Disruption of a single allele of the GLUT4 gene caused a decrease in adipocyte 
GLUT4 protein content and was shown to result in the development of a Type II diabetes -like phenotype [9]. Over-expression of GLUT4 using a fat-specific promoter protected against the development of insulin resistance that was associated with diabetes induced by streptozotocin [10]. Adipose-specific ablation of the GLUT4 gene resulted in insulin resistance, also in the liver and in skeletal muscle [11]. Moreover, despite evidence suggesting normal GLUT4 expression in skeletal muscle of diabetic patients $[12,13]$, GLUT4 expression could be selectively decreased in slow twitch fibres of skeletal muscle from diabetic patients [14]. These data outline the potential importance of decreased GLUT4 expression in the development of insulin resistance and Type II diabetes.

Based on these data, it is surprising that the understanding of mechanisms controlling GLUT4 gene expression in adipocytes under physiological and pathophysiological conditions is limited [15, 16]. For example, the GLUT4 gene is activated as part of the adipocyte differentiation program, largely controlled by PPAR $\gamma$ [17]. Yet a PPAR $\gamma$ binding site (PPRE) has not been identified in the GLUT4 promoter, suggesting that perhaps other transcription factors, like members of the C/EBPs family, are likely to mediate the activation of the GLUT4 gene $[18,19]$. Accordingly, repression of GLUT4 transcription by TNFalpha has been shown to occur in 3T3-L1 adipocytes through alterations in the binding of C/EBPs to the GLUT4 promoter [20,21]. Recently DNA sequence in the GLUT4 promoter spanning between nucleotides -676 and -706 , has been suggested to mediate the reduction in GLUT4 transcription by chronic insulin and a cAMP analogue $[22,23]$. This sequence, termed insulin responsive element (IRE), was shown to be required and sufficient for GLUT4 gene repression under these conditions in 3T3-L1 adipocytes. This IRE sequence in the GLUT4 promoter, was suggested to bind transcription factors of the NF1 family as well as additional, as yet unidentified, proteins [24]. DNA binding of NF1 transcription factors depends on conserved cysteins in their DNA binding domain [25], which could lead to high sensitivity of their DNA binding capacity in vivo to reactive oxygen species [26]. Oxidative stress is increasingly reported to occur in diabetes and was suggested to play a pathogenic role in various aspects of the disease and its complications $[27,28]$. Exposure of cultured cells to low micromolar $\mathrm{H}_{2} \mathrm{O}_{2}$ concentrations does result in insulin resistance [29-32]. In 3T3-L1 adipocytes, prolonged exposure to oxidative stress decreases GLUT4 protein and mRNA level $[29,33]$, contributing to the impairment in insulin-stimulated glucose uptake activity. Thus, we assessed whether the reduction in GLUT4 mRNA following prolonged oxidative stress is associated with decreased binding to the IRE sequence of the GLUT4 promoter and whether it involves impaired binding of NF1 transcription factors.

\section{Materials and methods}

Materials. Tissue culture medium, serum, and antibiotic solutions were obtained from Biological Industries (Bet Ha'emek, Israel). Recombinant human insulin was from Novo Nordisk (Bagsvaerd, Denmark). Peroxidase-conjugated anti-rabbit $\mathrm{IgG}$, anti-mouse IgG, $\left[\gamma{ }^{32} \mathrm{P}\right] \mathrm{ATP}$ and 2-Deoxy-[ $\left[{ }^{3} \mathrm{H}\right]$ glucose were from Amersham Life Sciences (Buckingham, UK). Anti-GLUT4 antibodies were from Chemicon International (Temecula, Calif., USA) and anti-NF1 from Santa Cruz Biotechnology (Santa Cruz Calif., USA). DNA probes were obtained from Sigma Genosys (Cambridgeshire, UK). All other chemicals were obtained from Sigma Chemical (St. Louis, Mo., USA).

Cell culture and treatment. 3T3-L1 pre-adipocytes (American type culture collection) were grown to confluence and were induced to differentiate in DMEM [30]. Cells were used 12 to 14 days after differentiation induction. $\mathrm{H}_{2} \mathrm{O}_{2}$ was generated by adding $12 \mathrm{mU} / \mathrm{ml}$ glucose oxidase [type II from Aspergillus niger, 20000 unit/g solid in non-oxygen-saturated conditions, Sigma Chemical (St Louis, Mo.)], to serum free DMEM supplemented with $0.5 \%$ radioimmunoassay grade bovine serum albumin (BSA).

Northern blot analysis. Total cellular RNA was extracted using Tri-Reagent (Molecular Research Center, Cincinnati, Ohio, USA). Northern blot analysis was carried out as described previously [29, 34].

Preparation of nuclear extracts. Nuclear extracts were prepared as previously described [21]. After the indicated treatments, adipocytes (ten dishes/treatment) were washed three times and scraped in PBS, after which cells were pelleted by centrifugation $\left(10 \mathrm{~min}, 3000 \mathrm{~g}\right.$ at $\left.4{ }^{\circ} \mathrm{C}\right)$. The pellet was re-suspended in five volumes of buffer A (10 mmol/l HEPES pH 7.9, $10 \mathrm{mmol} / \mathrm{l}$ $\mathrm{KCl}, 0.75 \mathrm{mmol} / \mathrm{l}$ spermidine, $0.15 \mathrm{mmol} / \mathrm{l}$ spermine, $0.1 \mathrm{mmol} /$ 1 EDTA, $0.1 \mathrm{mmol} / \mathrm{l}$ EGTA), followed by centrifugation $\left(10 \mathrm{~min}, 3000 \mathrm{~g}\right.$ at $\left.4{ }^{\circ} \mathrm{C}\right)$. The supernatant was discarded and the pellet was re-suspended in two volumes of buffer $\mathrm{A}$, then homogenized by ten strokes in a ground-glass homogenizer. The lysate was centrifuged $\left(10 \mathrm{~min}, 3000 \mathrm{~g}\right.$ at $\left.4{ }^{\circ} \mathrm{C}\right)$ and the pellet was re-suspended in two volumes of buffer $\mathrm{A}$ and centrifuged again as described above. The nuclei (pellet) were re-suspended in nine volumes of buffer containing $0.3 \mathrm{~mol} / 1 \mathrm{NaCl}, 1 \%$ Nonidat P40, $1 \mathrm{~mol} / \mathrm{l}$ urea, $25 \mathrm{mmol} / 1$ HEPES pH 7.6 and $1 \mathrm{mmol} / 1$ dithiothreitol (DTT), vortexed, after which nuclei were allowed to swell on ice for $15 \mathrm{~min}$. The chromatin was pelleted by centrifugation $\left(10 \mathrm{~min}, 10000 \mathrm{~g}\right.$ at $\left.4^{\circ} \mathrm{C}\right)$. The fat-chromatin precipitate was removed and the nuclear extracts were frozen and stored at $-80^{\circ} \mathrm{C}$.

Electrophoretic mobility shift assay (EMSA). The doublestranded oligonucleotides were radio-labelled using $[\gamma$ ${ }^{32} \mathrm{P}$ ]ATP and a T4 polynucleotide kinase (New England Biolabs, Beverly, Mass., USA). The following DNA probes were used: The IRE probe was an oligonucleotide corresponding to bases -710 to -674 of the GLUT4 promoter, (5'-CACCTGTCCCTTGGGTCCCCTCCAAGAACCAGTGTAGGATC-3'), [22]. The NF1 probe constituted A 27 bp oligonucleotide containing the NF1 binding site from adenovirus 2 

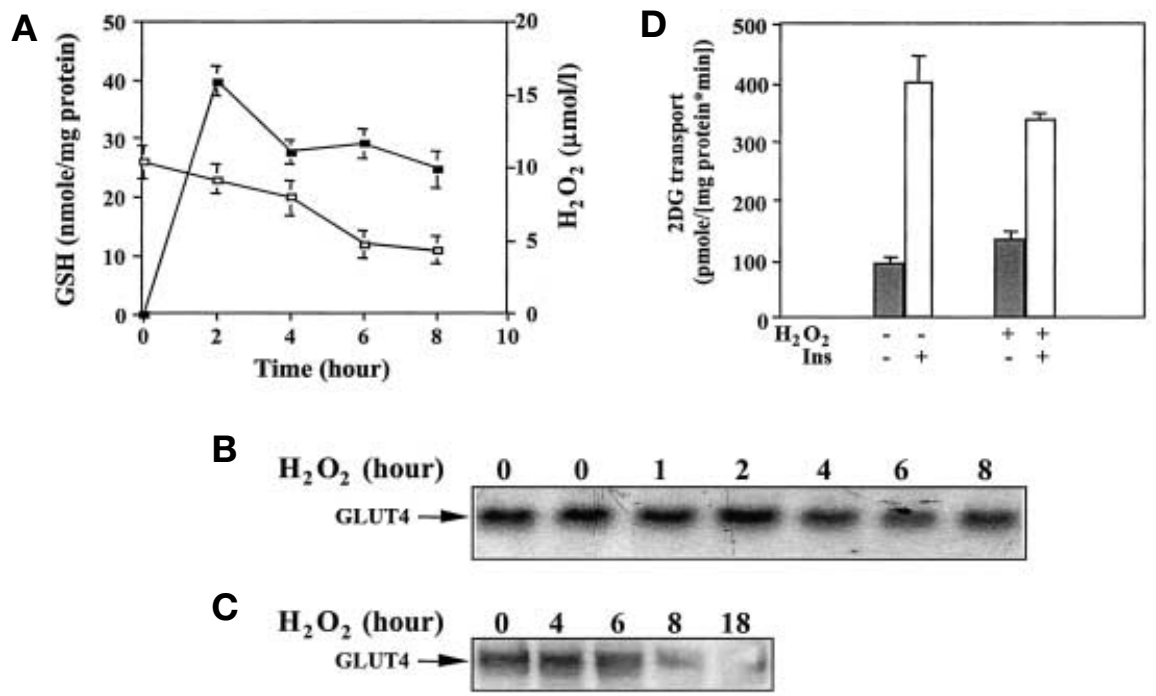

Fig.1. Effect of oxidative stress on intracellular GSH, GLUT4 mRNA, GLUT4 protein and insulin-stimulated glucose transport activity. 3T3-L1 adipocytes were exposed to oxidative stress $\left(\mathrm{H}_{2} \mathrm{O}_{2}\right)$ by adding glucose oxidase to the medium, as described in Methods. $\mathbf{A} \mathrm{H}_{2} \mathrm{O}_{2}$ concentration ( $\square$ ) was measured in the medium and gluthatione (GSH) ( $\square$ ) in cell extracts. Shown are the results of four experiments, carried out in duplicates. B $20 \mu \mathrm{g}$ of total RNA was separated and GLUT4 mRNA was analysed by northern blot analysis. Shown is a representative blot, done four additional times independently. C GLUT4 protein was analysed in total cell lysates. Shown is a blot representative of three independent experiments. D Untreated 3T3-L1 adipocytes and cells treated with $\mathrm{H}_{2} \mathrm{O}_{2}$ for $4 \mathrm{~h}\left(\mathrm{H}_{2} \mathrm{O}_{2}\right)$ were incubated with or without 100 $\mathrm{nmol} / \mathrm{l}$ of insulin for additional $20 \mathrm{~min}$. 2 deoxyglucose transport was measured and presented as means \pm SE of three independent experiments done in duplicate.

(5'-TTTTGGATTGAAGCCAATATGATAAAA-3') [24]. The PPRE probe was an oligonucleotide containing the classic PPRE from the promoter of the fatty acyl-CoA oxidase gene [35] (5'-AATTTCGAGAACGTGACCTTTGTCCTGGTCCAGCT-3'). The oligo for AP1 was composed of four repeats of the AP1 consensus binding site [36] (5'-TGACTCATGACTCATGACTCATGACTCA-3'). EMSA was carried out as described in [21], with some modifications. Briefly, 7 or $10 \mu \mathrm{g}$ of nuclear extracts (as indicated) and $1 \cdot 10^{6} \mathrm{cpm}{ }^{32} \mathrm{P}-\mathrm{la}-$ belled oligonucleotide, were incubated at room temperature for $60 \mathrm{~min}$ in reaction buffer $(0.33 \mathrm{~mol} / \mathrm{l}$ urea, $0.1 \mathrm{~mol} / \mathrm{l} \mathrm{NaCl}$, $0.33 \%$ Nonidat P40, 25 mmol/l HEPES pH 7.9, $10 \%$ glycerol, $5 \mu \mathrm{g}$ of acetylated BSA, $3 \mathrm{mg}$ of poly[dIdC], $10 \mathrm{mmol} / \mathrm{l} \mathrm{DTT}$, final volume $30 \mu \mathrm{l}$ ). Then, the reaction mixture was electrophoresed on $7 \%$ or $5 \%$ non-denaturing polyacrylamide gels. The gels were dried and exposed to X-ray film overnight and quantified by laser densitometry. Specifity of binding was ascertained by competition with a 250 -fold molar excess of the respective unlabelled oligonucleotide.

Other measurements. 2-deoxyglucose uptake, and western blot analysis were done as described previously [33]. GSH was measured spectrophotometrically by the DTNB-GSSG reductase recycling assay, as described [37]. Medium $\mathrm{H}_{2} \mathrm{O}_{2}$ concentration was measured by a method published previously [38].
Measurements of protein concentration were done using the Bio-Rad Bradford reagent.

Statistical analysis. Data are expressed as means \pm standard error (SE). Each treatment was compared to control, and statistical significance between the two groups was evaluated using the Student's $t$ test. The criterion for significance was set at a $p$ value of less than 0.05 .

\section{Results}

Oxidative stress decreases GLUT4 expression. To assess the effect of prolonged, low-grade oxidative stress on GLUT4 expression, glucose oxidase was added to serum deprived medium of fully differentiated 3T3-L1 adipocytes. The medium $\mathrm{H}_{2} \mathrm{O}_{2}$ concentrations and cellular GSH concentrations when $12 \mathrm{mU} / \mathrm{ml}$ glucose oxidase was added to the medium are shown (Fig. $1 \mathrm{~A}$ ). $\mathrm{H}_{2} \mathrm{O}_{2}$ concentrations rapidly reached a steady state of about $11 \mu \mathrm{mol} / 1$, which remained stable over the $8 \mathrm{~h}$ incubation period. Concomitantly, cellular GSH progressively decreased. These conditions were not associated with a noticeable loss of cell viability, as assessed by both protein recovery and MTT assay.

To determine the effect of low grade, prolonged oxidative stress on GLUT4 expression, GLUT4 mRNA content was assessed using northern blot analysis. The decrease in cellular GLUT4 mRNA over the $8 \mathrm{~h}$ incubation period is shown (Fig. 1B). Decreased GLUT4 mRNA could be observed as early as after $4 \mathrm{~h}$ exposure to oxidative stress. The down-regulation in GLUT4 mRNA was reflected in $40 \pm 10$ and $63 \pm 15 \%$ reduction of GLUT4 protein content after $8 \mathrm{~h}$ and $18 \mathrm{~h}$ exposure to $\mathrm{H}_{2} \mathrm{O}_{2}$, respectively (Fig. 1C). After 4 hours exposure to oxidative stress, only a non-significant reduction $(p=0.21)$ in insulin stimulated glucose transport (ISGT) was evident (Fig.1D) and was accompanied by increased basal glucose transport. The reduction in ISGT has been 

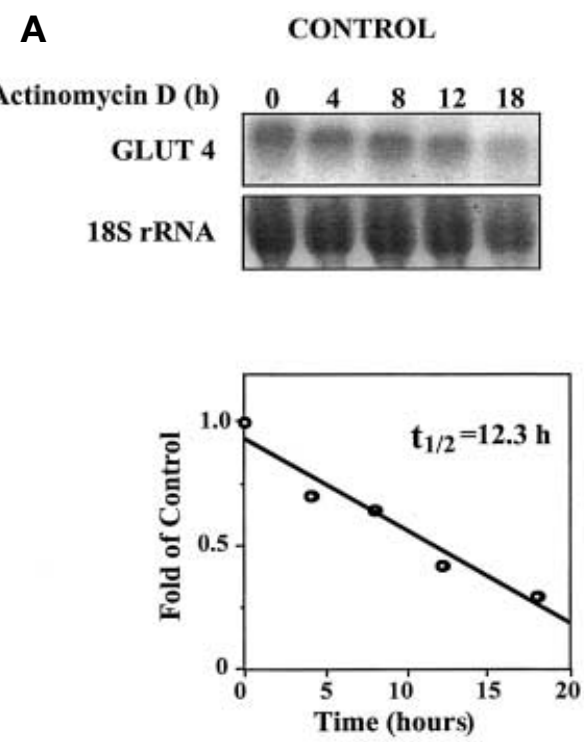

Fig. 2. The effect of prolonged oxidative stress on GLUT 4 mRNA stability. Total RNA was isolated from 3T3-L1 adipicytes exposed to either actinomycin $\mathrm{D}(5 \mu \mathrm{g} / \mathrm{ml})$ alone $(\mathbf{A})$ or to actinomycin $\mathrm{D}$ in the presence of $\sim 11 \mu \mathrm{mol} / 1 \mathrm{H}_{2} \mathrm{O}_{2}$ generated as described above (B), for the indicated times. $20 \mu \mathrm{g}$ of total RNA were electrophoresed and analysed by northern blot analysis. $18 \mathrm{~S}$ ribosomal RNA was used as a standard. The hybridization pattern was analysed by densitometric scanning, the data plotted as fold of the mRNA band intensity in time 0 , and the $\mathrm{t}_{1 / 2}$ of the GLUT4 mRNA degradation was calculated. Shown is a representative experiment carried out two times

shown to become more pronounced when extending the incubation period to $18 \mathrm{~h}$ exposure $[29,33]$. To gain further insight on the cellular mechanism responsible for the decrease in GLUT4 mRNA induced by oxidative stress, the stability of the GLUT4 transcript was assessed using the transcription inhibitor actinomycin D. Two independent experiments, of which one representative is shown in Figure 2, resulted in only a minor decrease in GLUT4 mRNA stability after oxidative stress (from 12.3 to $10.3 \mathrm{~h}$ in control and $\mathrm{H}_{2} \mathrm{O}_{2}$ treated cells, respectively). Since this degree of reduction in mRNA stability could not quantitatively explain the reduction in steady state GLUT4 mRNA, transcriptional repression of the GLUT4 gene appears as a major mechanism by which oxidative stress decreases the steady state content of GLUT4 mRNA.

The effect of oxidative stress on binding capacity of nuclear proteins to the insulin responsive element (IRE) in the GLUT4 promoter. We assessed whether the decreased GLUT4 mRNA is associated with reduced DNA binding capacity of nuclear proteins to the IRE sequence in the mouse GLUT4 promoter, a major regulatory element of GLUT4 transcription. Nuclear protein extracts were prepared from 3T3-L1
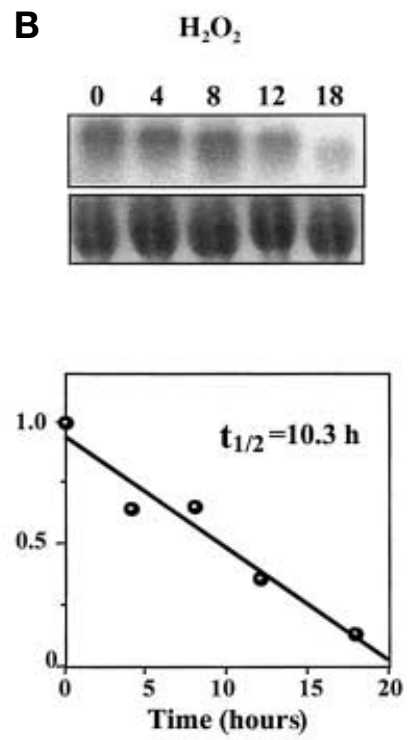

adipocytes exposed to oxidative stress and subsequently incubated with a radio-labelled oligonucleotide corresponding to the -676 to -706 sequence in the mouse GLUT4 gene. Nuclear protein extract from cells exposed for $4 \mathrm{~h}$ to about $11 \mu \mathrm{mol} / 1 \mathrm{H}_{2} \mathrm{O}_{2}$ displayed a decreased capacity to bind to the IRE oligo as assessed by EMSA (Fig. 3A). The specificity of the binding reaction to the IRE oligo was shown using complete inhibition of protein-DNA complex formation by a 250 -fold excess of unlabelled IRE oligo to the binding reaction (lane $U$ ). An unrelated oligo showed no similar capacity to compete with the binding to the IRE sequence (not shown). The graph summarizes densitometry analyses of the band derived from seven independent experiments and shows a $40 \%(p=0.001)$ reduction in its intensity. This reduction was apparent after $1 \mathrm{~h}$ exposure to oxidative stress and was maximal at $4 \mathrm{~h}$ (data not shown). Exposure for $4 \mathrm{~h}$ to less than $4 \mu \mathrm{mol} / 1 \mathrm{H}_{2} \mathrm{O}_{2}$ did not have a meaningful effect on IRE binding (data not shown). To exclude the possibility that the reduction in binding to the IRE sequence was caused by a non-specific toxic effect of the oxidative stress conditions used, binding to other DNA sequences was assessed. Using the consensus DNA sequence for the binding of transcription factors of the peroxisome proliferator activator receptor (PPAR) family no significant decrease $(p=0.18)$ in nuclear protein binding capacity could be detected following oxidative stress (Fig.3B). When an AP-1 binding sequence was used, increased binding of nuclear proteins was observed in cells exposed to oxidative stress (Fig. 3C), confirming that the conditions used induced a known biological response to oxidative stress. Together, these EMSA studies suggest that oxidative stress induced a specific decrease in the DNA binding capacity to the IRE sequence in the GLUT4 promoter. 

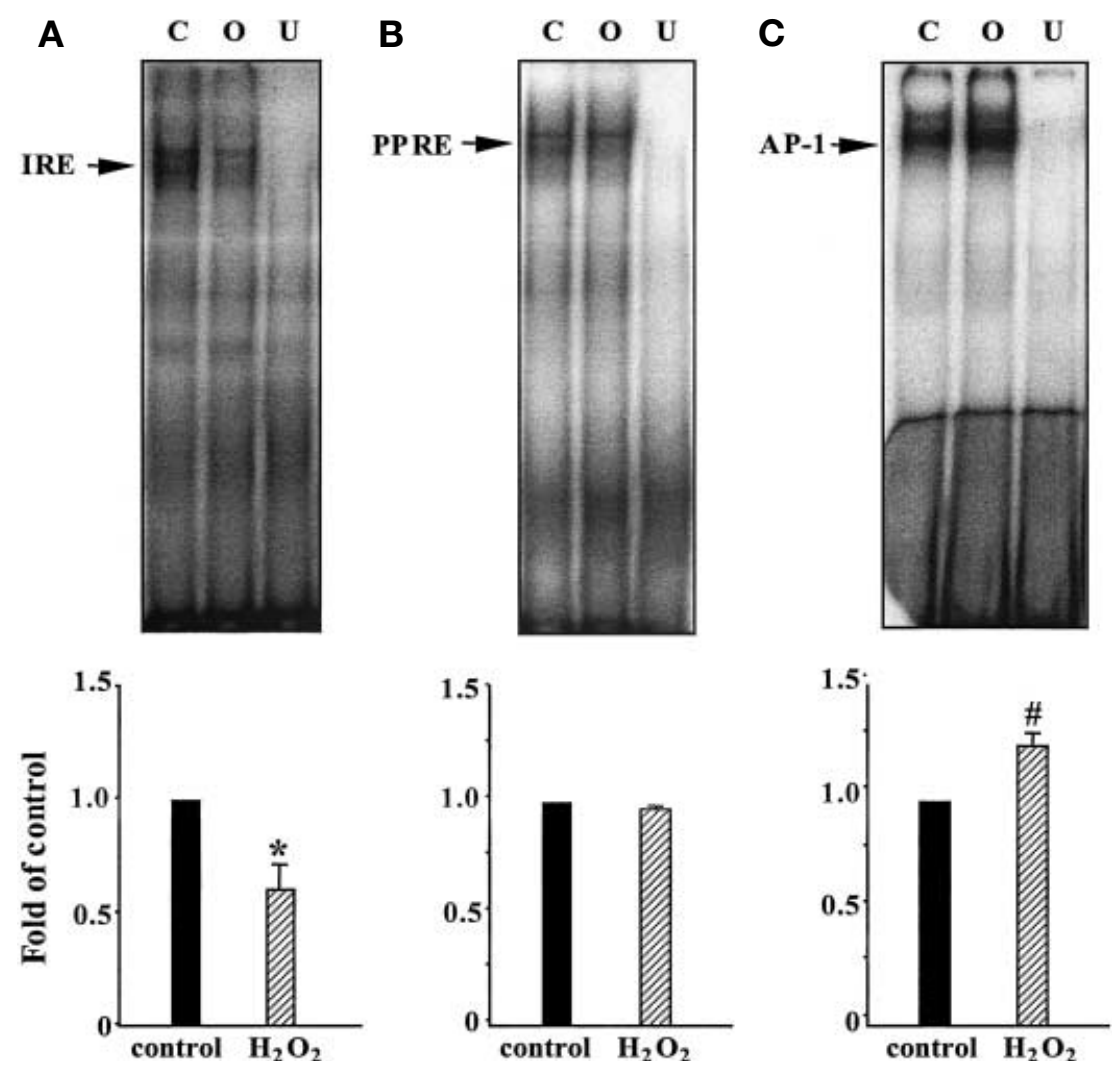

Fig.3. Oxidative stress impairs the binding capacity of nuclear proteins to the insulin responsive element (IRE) sequence in the GLUT4 promoter. $7 \mu \mathrm{g}$ of nuclear extract from untreated 3T3-L1 adipocytes (C) and from oxidized cells $\left(\mathrm{H}_{2} \mathrm{O}_{2}\right.$ for $\left.4 \mathrm{~h}\right)$ (O), were used for EMSA with either the IRE (A), PPRE (B) and AP-1 (C) radio-labelled oligonucleotide, as described in Methods. A 250-fold excess of the respective unlabelled oligonucleotide (U) was added as a competitor. The upper panels show auto-radiographs representative of seven independent experiments, whereas the graph below each picture represents the means \pm SE of densitometry analysis. All values are expressed as fold of the intensity of the band observed in non-oxidized cells. ${ }^{*} p=0.0011$ vs control ${ }^{\#} p=0.0003$ vs control

The involvement of SH groups in mediating the effect of oxidative stress on binding of nuclear proteins to the IRE sequence. To further establish the role of oxidative stress and of critical sulfhydryl groups in causing the decreased binding of nuclear proteins to the IRE sequence, in vitro oxidation of nuclear extracts was done. Nuclear protein extracts from control cells were oxidized using either the $\mathrm{SH}$ alkylating reagents $\mathrm{N}$-ethylmaleimide (NEM), diamide, or $\mathrm{H}_{2} \mathrm{O}_{2}$. Subsequently, the extracts were treated with or without DTT, a reducing agent. The binding capacity to the IRE was then assessed (Fig. 4A). In vitro oxidation of nuclear extracts using diamide or NEM completely inhibited the binding capacity to the IRE oligo. In vitro oxidation with $2.5 \mathrm{mmol} / 1 \mathrm{H}_{2} \mathrm{O}_{2}$ also resulted in decreased binding to the IRE sequence, though to a much lesser degree than seen for the other SH re- agents. These decrements in the binding to the IRE oligo were reversible by DTT treatment. Following diamide and $\mathrm{H}_{2} \mathrm{O}_{2}$, a full reversibility of the IRE binding capacity could be shown after DTT but only minimally when the extracts were treated with NEM. To assess whether in vivo oxidation also affected IRE binding as a result of a reversible, SH-dependent process, 3T3-L1 adipocytes were treated with glucose oxidase and nuclear extracts were prepared and treated in vitro with or without DTT. For this set of experiments, the DNA binding reaction of the nuclear protein extract was carried out either in the complete absence or presence of $60 \mathrm{mmol} / \mathrm{l} \mathrm{DTT}$. The complete absence of DTT in the binding reaction resulted in a dramatic reduction in IRE binding of nuclear proteins prepared from oxidized cells (Fig $4 \mathrm{~B}$, lanes $\mathrm{O}$ - compared to $\mathrm{C}-$ ), exceeding the $40 \%$ decrease shown in Figure 2A. Whereas the addition of DTT to the binding reaction had no effect on IRE binding of nuclear extracts prepared from control cells, it partially but significantly $(p<0.01$ densitometry values) reversed the decrease in binding induced by in vivo oxidation. These data suggest that the DNA binding capacity of nuclear proteins to the IRE sequence is sensitive to oxidation, partially reversible, and depends on the presence of critical SH groups.

Since the IRE sequence contains a putative binding element for NF1 transcription factors, we assessed NF1 protein content and DNA binding to the consensus sequence for NF1 binding. A Western 


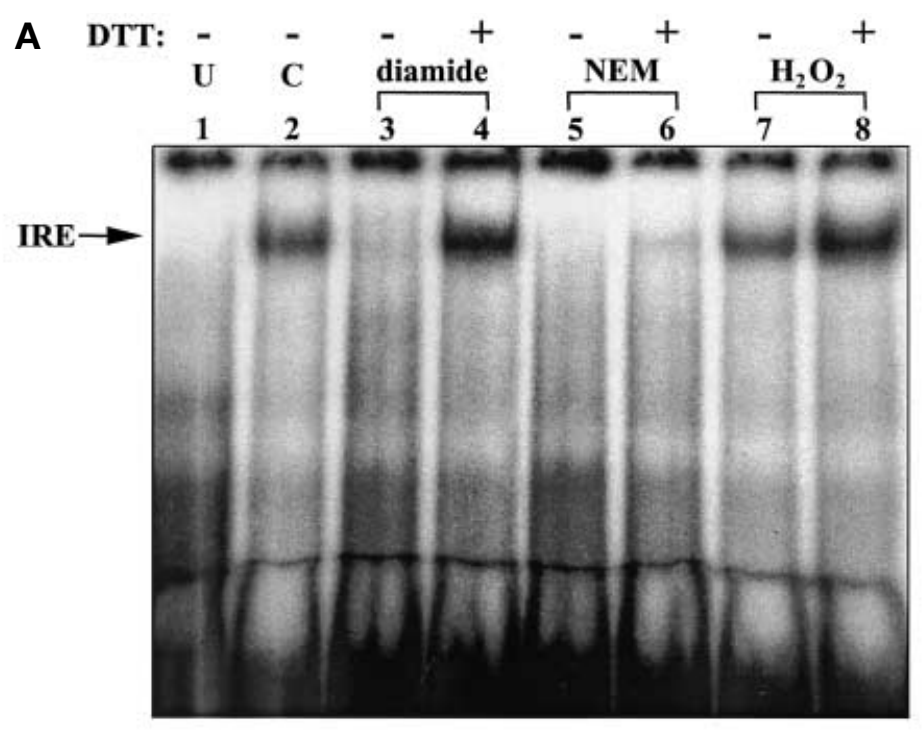

B

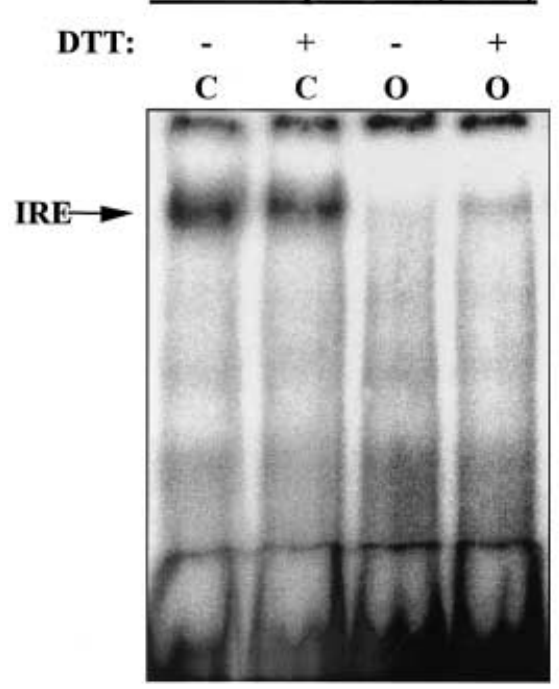

\section{Long exposure (48 h)}

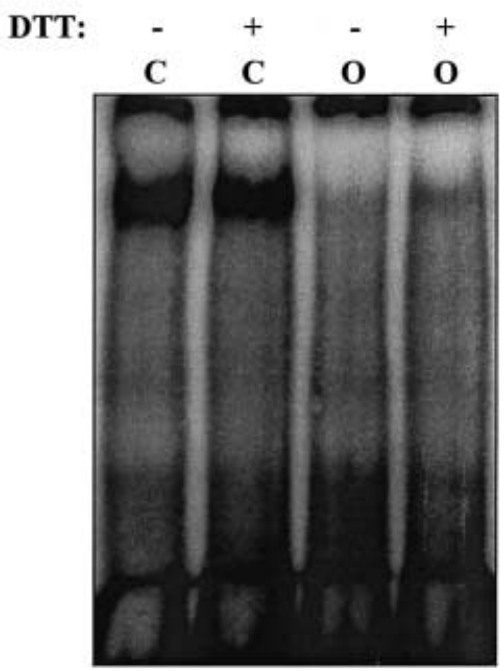

Fig. 4. Reversibility by DTT of the decreased DNA binding of nuclear extracts to the IRE sequence following in vitro and in vivo oxidation. A $7 \mu \mathrm{g}$ of nuclear extract from untreated 3T3L1 adipocytes was incubated without (C) or with either $0.1 \mathrm{mmol} / \mathrm{l}$ diamide, $0.2 \mathrm{mmol} / \mathrm{l} \mathrm{NEM}$, or $2.5 \mathrm{mmol} / 1 \mathrm{H}_{2} \mathrm{O}_{2}$ for $5 \mathrm{~min}$ on ice, followed by another $5 \mathrm{~min}$ incubation with or without $60 \mathrm{mmol} / \mathrm{l}$ DTT. U designates untreated nuclear extracts in which a 250-fold excess of unlabelled IRE oligonucleotide was added as a competitor. Shown is an auto-radiograph representing two additional experiments yielding similar results. B, C $7 \mu \mathrm{g}$ of nuclear extract from untreated 3T3-L1 adipocytes $(C)$ and from oxidized cells treated with $\mathrm{H}_{2} \mathrm{O}_{2}$ for $4 \mathrm{~h}$ (O), were incubated in the presence or absence of $60 \mathrm{mmol} / \mathrm{l}$ DTT for $5 \mathrm{~min}$ on ice. EMSA was then done without adding any additional DTT to the binding reaction and auto-radiographs after either $18 \mathrm{~h}$ exposure (left) or $48 \mathrm{~h}$ exposure (right) are shown. This experiment was done two times with identical results blot analysis of cell lysates using a commercial NF1 antibody is shown (Fig 5A). This antibody recognises proteins with molecular weights of 33, 54 and 120 $\mathrm{kDa}$, which correspond to two of the known isoforms of NF1 proteins and a potential dimer, respectively. Exposure of the cells to oxidative stress did not result in a pronounced change in any of these bands, suggesting that decreased content of the NF1 proteins recognised by this antibody could not explain the reduced binding to the IRE sequence. When the capacity of nuclear proteins to bind the consensus sequence for NF1 binding was measured, a $16 \pm 2.3 \%$ $(p=0.0013)$ reduction in protein-DNA complex formation was observed in the oxidized cells (Fig. 5B). The specificity of the binding to the consensus binding sequence for NF1 was established using a 250fold excess of unlabelled probe (lane $\mathrm{U}$ ). 

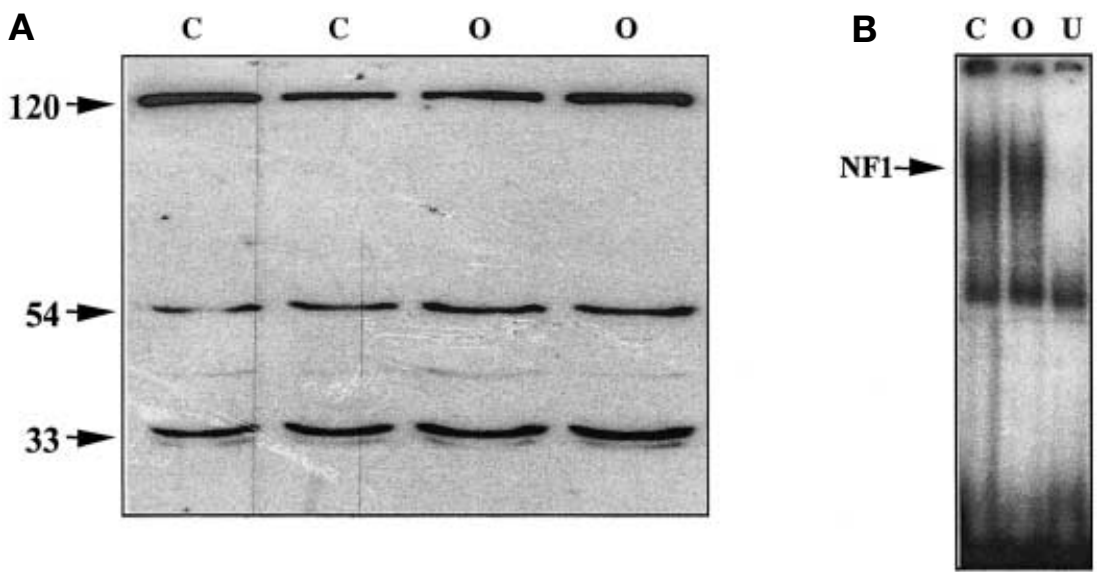

Fig. 5. The effect of oxidation on NF1 protein content and binding to a consensus binding DNA sequence for NF1. A Western blot analysis of NF1 proteins in cell lysates from either control $(\mathrm{C})$ or oxidized $(\mathrm{O})$ 3T3-L1 adipocytes using antiNF1 (N-terminus) antibodies. Shown is a blot representing three independent experiments. B $10 \mu \mathrm{g}$ of nuclear extract from control 3T3-L1 adipocytes $(\mathrm{C})$ and from cells treated with $\mathrm{H}_{2} \mathrm{O}_{2}$ for $4 \mathrm{~h}(\mathrm{O})$ were used for EMSA using radio-labelled oligonucleotide which contains the consensus NF1 binding sequence. A 250-fold excess of unlabelled NF1 oligonucleotide (U) was added as a competitor. Shown is a an auto-radiograph representing six independent experiments

\section{Discussion}

This study found decreased DNA binding of nuclear proteins from 3T3-L1 adipocytes to the IRE sequence in the GLUT4 promoter following exposure to oxidative stress. This finding could provide a putative mechanism by which prolonged, low-grade oxidative stress induces decreased GLUT4 mRNA content, resulting in lower GLUT4 protein content which contributes to the induction of impaired insulin-stimulated glucose uptake.

The biological responses of various cultured cells to insulin have been shown to be impaired by micromolar $\mathrm{H}_{2} \mathrm{O}_{2}$ concentrations [29-32,39]. In cells representing the metabolic target tissues of insulin such as 3T3L1 adipocytes, this effect of oxidative stress causes insulin resistance, including impaired insulin-stimulated glucose uptake activity [29, 30, 39]. The mechanisms underlying this phenomenon appear to be complex and depend on the duration and intensity of the oxidative insult. For example, $2 \mathrm{~h}$ incubation with $\mathrm{H}_{2} \mathrm{O}_{2}$ generating system has been shown to impair GLUT4 translocation by interfering with normal activation of the insulin-signalling cascade $[30,40]$. When longer incubation periods were used, a reciprocal effect on the expression of the two glucose transporters in these cells has been noted, with GLUT1 being up-regulated while GLUT4 down-regulated, at both the protein and mRNA levels [29]. We therefore aimed to gain further insight on the mechanisms responsible for de- creased GLUT4 mRNA content by oxidative stress. Decreased steady state mRNA content could in principle result from either transcriptional repression of the GLUT4 gene, and/or increased degradation of the GLUT4 mRNA transcripts. Multiple inducers of insulin resistance in 3T3-L1 adipocytes, including chronic insulin [22, 24], TNF alpha [20,41], arachidonic acid [35, 42], and cAMP [23], have also been shown to make use of these two basic mechanisms in inducing decreased GLUT4 expression. Oxidative stress had only a minor effect on the stability of preformed GLUT4 mRNA transcripts (Fig. 2), which could not explain the reduction in its content (Fig. 1B). Therefore we evaluated possible mechanisms for transcriptional repression of the GLUT4 gene.

The notion that oxidative stress could affect DNA binding of transcription regulating factors is well established, and could be caused by diverse mechanisms $[43,44]$. Both direct oxidation of specific moieties such as $\mathrm{SH}$ groups in domains critical for transcription factors' function (like the DNA binding domain), decreased expression, and alteration in the phosphorylation state, have all been documented. The in vitro studies reported herein, show that oxidation of nuclear protein extracts by either $\mathrm{H}_{2} \mathrm{O}_{2}$, the $\mathrm{SH}$ alkylating agent NEM, or diamide, result in decreased proteinDNA complex formation. This finding suggests that oxidative stress could directly affect DNA binding capacity of preformed nuclear proteins (Fig. 4A). The fact that the reducing agent DTT could reconstitute at least partly the reduction in DNA binding of nuclear proteins extracted from oxidized cells (Fig. 4B), also supports the notion that the direct oxidation of transcription factors occurs in these cells.

The relevance of these findings to GLUT4 repression is suggested in that oxidative stress impaired DNA binding to the IRE sequence in the GLUT4 promoter. This effect was sequence-specific, as no similar decrease in protein-DNA complex formation could be observed with the consensus sequence for either PPAR $\gamma$ or AP1 binding (Fig. 3A-C). The IRE is a cis-element located about $700 \mathrm{~kb}$ upstream of the transcription initiation site of the murine 
GLUT4 gene and a sequence with $74 \%$ homology was identified in the human GLUT4 promoter [22]. This sequence was recently identified to mediate GLUT4 repression in response to chronic insulin and 8-Br-cAMP using promoter-reporter studies and DNase1 footprinting $[22,23]$. The proteins that bind to the IRE sequence and how GLUT4 repressors alter their function, have only been partly characterized. In 3T3-L1 adipocytes, members of the NF1 transcription factor family bind an element within the IRE, which resembles their consensus DNA binding sequence [23, 24]. However, additional, as yet unidentified proteins, also seem to contribute to the DNAprotein complexes observed in EMSA [24]. In addition to the identity of the proteins that bind IRE, it is not clear how transcriptional regulation occurs utilizing this regulatory sequence. Insulin and $8-\mathrm{Br}-$ cAMP, while utilizing the IRE in down-regulating GLUT4 transcription, do not induce decreased DNA binding to this sequence as assessed by EMSA. This disparity between DNA binding capacity and transcriptional control suggests other mechanisms that affect the activity of transcription factors. In GLUT4 repression by insulin, the NF1 transcription factors have been implicated and were shown to undergo rapid and transient phosphorylation [24]. In contrast, we show decreased nuclear protein binding to the IRE sequence after oxidative stress as assessed by EMSA (Fig. 3A, and Fig. 4B), which was partially reversible when the nuclear proteins were treated in vitro with the reducing agent DTT (Fig. 4B). Since the DNA binding capacity of NF1 transcription factors has been shown to be highly sensitive to oxidative stress [25], the possibility that a decreased NF1IRE association could explain the impaired proteinDNA complex formation after oxidative stress was raised. Nuclear proteins of oxidized cells showed only a mild $(16 \%)$, albeit significant $(p=0.04)$, decrease in binding to the consensus DNA binding sequence for NF1, which could not be explained by a decreased expression of at least three of its known isoforms. These data suggest that decreased NF1 binding to the IRE could contribute but can not fully explain, the full extent of the decrease in DNA binding to this regulatory sequence in the GLUT4 promoter. Therefore, the identity of additional IRE binding proteins that are affected by oxidative stress has yet to be determined. Moreover, as various posttranslational modifications of transcription factors are described [45], the full contribution of NF1 proteins in mediating GLUT4 repression by oxidative stress has yet to be clarified.

In conclusion, this study found that prolonged oxidative stress results in decreased GLUT4 mRNA, associated with decreased DNA binding of nuclear proteins to the IRE sequence of the GLUT4 gene promoter. This could be caused by direct and reversible oxidation of oxidation-sensitive moieties in transcrip- tion factors, ultimately contributing to the induction of insulin resistance.

Acknowledgements. This work was funded by the Israel Science Foundation founded by the Israeli Academy of Sciences and Humanities.

\section{References}

1. Shepherd PR, Kahn BB (1999) Glucose transporters and Insulin action-implications for Insulin resistance and diabetes mellitus. N Engl J Med 341: 248-257

2. Tirosh A, Rudich A, Bashan N (2000) Regulation of glucose transporters-implications for Insulin resistance states. J Pediatr Endocrinol Metab 13: 115-133

3. Abel EI, Shepherd PR, Kahn BB (1996) Glucose transporters and pathophysiologic states. In: LeRoith D, Taylor SI, Olefsky JM (eds) Diabetes Mellitus. Lippincott-Raven, Philadelphia New York, pp 530-543

4. Carvalho E, Jansson PA, Nagaev I, Wenthzel AM, Smith U (2001) Insulin resistance with low cellular IRS-1 expression is also associated with low GLUT4 expression and impaired Insulin-stimulated glucose transport. FASEB J 15: 1101-1103

5. Sivitz WI, DeSautel SL, Kayano T, Bell GI, Pessin JE (1989) Regulation of glucose transporter messenger RNA in Insulin-deficient states. Nature 340: 72-74

6. Olson AL, Liu ML, Moye-Rowley WS, Buse JB, Bell GI, Pessin JE (1993) Hormonal/metabolic regulation of the human GLUT4/muscle-fat facilitative glucose transporter gene in transgenic mice. J Biol Chem 268: 9839-9846

7. Olson AL, Pessin JE (1995) Transcriptional regulation of the human GLUT4 gene promotor in diabetic transgenic mice. J Biol Chem 270: 23491-23495

8. Gerrits PM, Olson AL, Pessin JE (1993) Regulation of the GLUT4/muscle-fat glucose transporter mRNA in adipose tissue of insulin-deficient diabetic rats. J Biol Chem 268: 640-644

9. Stenbit AE, Tsao TS, Li J et al. (1997) GLUT4 heterozygous knockout mice develop muscle insulin resistance and diabetes. Nat Med 3: 1096-1101

10. Tozzo E, Gnudi L, Kahn BB (1997) Amelioration of insulin resistance in streptozotocin diabetic mice by transgenic overexpression of GLUT4 driven by an adipose-specific promoter. Endocrinology 138: 1604-1611

11. Abel ED, Peroni O, Kim JK et al. (2001) Adipose-selective targeting of the GLUT4 gene impairs insulin action in muscle and liver. Nature 409: 729-733

12. Pedersen O, Bak JF, Andersen PH et al. (1990) Evidence against altered expression of GLUT1 or GLUT4 in skeletal muscle of patients with obesity or NIDDM. Diabetes 39: 865-870

13. Garvey WT, Maianu L, Hancock JA, Golichowski AM, Baron A (1992) Gene expression of GLUT4 in skeletal muscle from insulin-resistant patients with obesity, IGT, GDM, and NIDDM. Diabetes 41: 465-475

14. Gaster M, Staehr P, Beck-Nielsen H, Schroder HD, Handberg A (2001) Glut4 is reduced in slow muscle fibers of type 2 diabetic patients: is insulin resistance in type 2 diabetes a slow, type 1 fber disease? Diabetes 50: 1324-1329

15. Ezaki O (1997) Regulatory elements in the insulin-responsive glucose transporter (GLUT4) gene. Biochem Biophys Res Commun 241: 1-6

16. Olson AL, Pessin JE (1996) Transcriptional regulation of GLUT4 gene expression. Semin Cell Dev Biol 7: 287-293 
17. Wu Z, Xie Y, Morrison RF, Bucher NL, Farmer SR (1998) PPARgamma induces the insulin-dependent glucose transporter GLUT4 in the absence of C/EBPalpha during the conversion of $3 \mathrm{~T} 3$ fibroblasts into adipocytes. J Clin Invest 101: $22-32$

18. Lin FT, Lane MD (1992) Antisense CCAAT/enhancerbinding protein RNA suppresses coordinate gene expression and triglyceride accumulation during differentiation of 3T3-L1 preadipocytes. Genes Dev 6: 533-544

19. Lin FT, Lane MD (1994) CCAAT/enhancer binding protein alpha is sufficient to initiate the 3T3-L1 adipocyte differentiation program. Proc Natl Acad Sci USA 91: 8757-8761

20. Stephens JM, Pekala PH (1991) Transcriptional repression of the GLUT4 and C/EBP genes in 3T3-L1 adipocytes by tumor necrosis factor-alpha. J Biol Chem 266: 21839-21845

21. Jain R, Police S, Phelps K, Pekala PH (1999) Tumour necrosis factor-alpha regulates expression of the CCAAT-enhancer-binding proteins (C/EBPs) alpha and beta and determines the occupation of the $\mathrm{C} / \mathrm{EBP}$ site in the Promoter of the insulin-responsive glucose-transporter gene in 3T3L1 adipocytes. Biochem J 338: 737-743

22. Cooke DW, Lane MD (1998) A sequence element in the GLUT4 gene that mediates repression by insulin. J Biol Chem 273: 6210-6217

23. Cooke DW, Lane MD (1999) Transcriptional factor 1 mediates repression of the GLUT4 promoter by cyclic-AMP. Biochem Biophys Res Commun 260: 600-604

24. Cooke DW, Lane MD (1999) The transcription factor nuclear factor I mediates repression of the GLUT4 promoter by insulin. J Biol Chem 274: 12917-12924

25. Bandyopadhyay S, Gronostajski RM (1994) Identification of a conserved oxidation-sensitive cysteine residue in the NF 1 family of DNA-binding proteins. J Biol Chem 269: 29949-29955

26. Morel Y, Mermod N, Barouki R (1999) An autoregulatory loop controlling CYP1A1 gene expression: role of $\mathrm{H} 202$ and NF1. Mol Cell Biol 19: 6825-6832

27. Baynes JW (1991) Role of oxidative stress in development of complications in diabetes. Diabetes 40: 405-412

28. Wolff SP, Jiang ZY, Hunt JV (1991) Protein glycation and oxidative stress in diabetes mellitus and ageing. Free Radic Biol Med 10: 339-352

29. Rudich A, Kozlovsky N, Potashnik R, Bahan N (1997) Oxidant stress reduces insulin responsiveness in 3T3-L1 adipocytes. Am J Physiol Endocrinol Metab) 272: E935-E940

30. Tirosh A, Potashnik R, Bashan N, Rudich A (1999) Oxidative stress disrupts insulin-induced cellular redistribution of insulin receptor substrate-1 and phosphatidylinositol 3-kinase in 3T3-Ll adipocytes. J Biol Chem 274: 10595-10602

31. Hansen LL, Ikeda Y, Olsen GS, Busch AK, Mosthaf L (1999) Insulin signaling is inhibited by micromolar concentrations of H202. Evidence for a role of H202 in tumor necrosis factor-mediated insulin resistance. J Biol Chem 274: 25078-25084
32. Blair AS, Hajduch E, Litherland GJ, Hundal HS (1999) Regulation of Glucose Transport and Glycogen Synthesis in L6 Muscle Cells during Oxidative Stress. Evidence for cross-talk between the insulin and SAPK2/p38 mitogen-activated protein kinase signaling pathways. J Biol Chem 274: 36293-36299

33. Rudich A, Tirosh A, Potashnik R, Hemi R, Kannety H, Bashan N (1998) Prolonged oxidative stress impairs insulininduced GLUT4 translocation in 3T3-L1 adipocytes. Diabetes 47: 1562-1569

34. Bashan N, Burdett E, Guma A et al. (1993) Mechanisms of adaptation of glucose transporters to changes in the oxidative chain of muscle and fat cells. Am J Physiol 264: C430-C440

35. Long SD, Pekala PH (1996) Regulation of GLUT4 gene expression by arachidonic acid. Evidence for multiple pathways, one of which requires oxidation to prostaglandin E2. J Biol Chem 271: 1138-1144

36. Tamir A, Isakov N (1994) Cyclic AMP inhibits phosphatidylinositol-coupled and -uncoupled mitogenic signals in $\mathrm{T}$ lymphocytes. Evidence that cAMP alters PKC-induced transcription regulation of members of the jun and fos family of genes. J Immunol 152: 3391-3399

37. Anderson ME (1985) Determination of glutathione and glutathione disulfide in biological samples. Methods Enzymol 113: 548-555

38. Thurman RG, Ley HG, Scholz R (1972) Hepatic microsomal ethanol oxidation. Eur J Biochem: 420-430

39. Maddux BA, See W, Lawrence JCJ, Goldfine AL, Goldfine ID, Evans JL (2001) Protection against oxidative stress-induced insulin resistance in rat L6 muscle cells by mircomolar concentrations of alpha-lipoic acid. Diabetes 50: 404-410

40. Tirosh A, Rudich A, Potashnik R, Bashan N (2001) Oxidative stress impairs inuslin but not platelet-derived growth factor signaliing in 3T3-Ll adipocytes. Biochem J 355: 757-763

41. Stephens JM, Pekala PH (1992) Transcriptional repression of the C/EBP-alpha and GLUT4 genes in 3T3-L1 adipocytes by tumor necrosis factor-alpha. Regulations is coordinate and independent of protein synthesis. J Biol Chem 267: 13580-13584

42. Tebbey PW, McGowan KM, Stephens JM, Buttke TM, Pekala PH (1994) Arachidonic acid down-regulates the insulin-dependent glucose transporter gene (GLUT4) in 3T3L1 adipocytes by inhibiting transcription and enhancing mRNA tumover. J Biol Chem 269: 639-644

43. Sen CK, Packer L (1996) Antioxidant and redox regulation of gene transcription. FASEB J 10: 709-720

44. Morel Y, Barouki R (1999) Repression of gene expression by oxidative stress. Biochem J 342: 481-496

45. Berk AJ (1989) Regulation of eukaryotic transcription factors by post translational modification. Biochim Biophys Acta 1009: 103-109 